\title{
Correction to: Study on the identification and dynamics of green vision rate in Jing'an district, Shanghai based on deeplab V $3+$ model
}

\author{
Aiping Gou ${ }^{1} \cdot$ Chi Zhang ${ }^{1} \cdot$ Jiangbo Wang ${ }^{2}(\mathbb{D}$
}

Published online: 2 December 2021

๑) Springer-Verlag GmbH Germany, part of Springer Nature 2021

\section{Correction to: Earth Science Informatics}

https://doi.org/10.1007/s12145-021-00691-6

In the original published version of this article, the Figure 1 contained errors and the Funding information has been added. The authors requested that these be noted. The correct figure and the updated Acknowledgment are now presented as follows:

The original article can be found online at https://doi.org/10.1007/ s12145-021-00691-6.

Jiangbo Wang

wjb623@163.com

1 Landscape Architecture Department, Ecology School, Shanghai Institute of Technology, Shanghai, China

2 Department of Architecture, Nanjing Tech University, Nanjing 211816, Jiangsu, China 


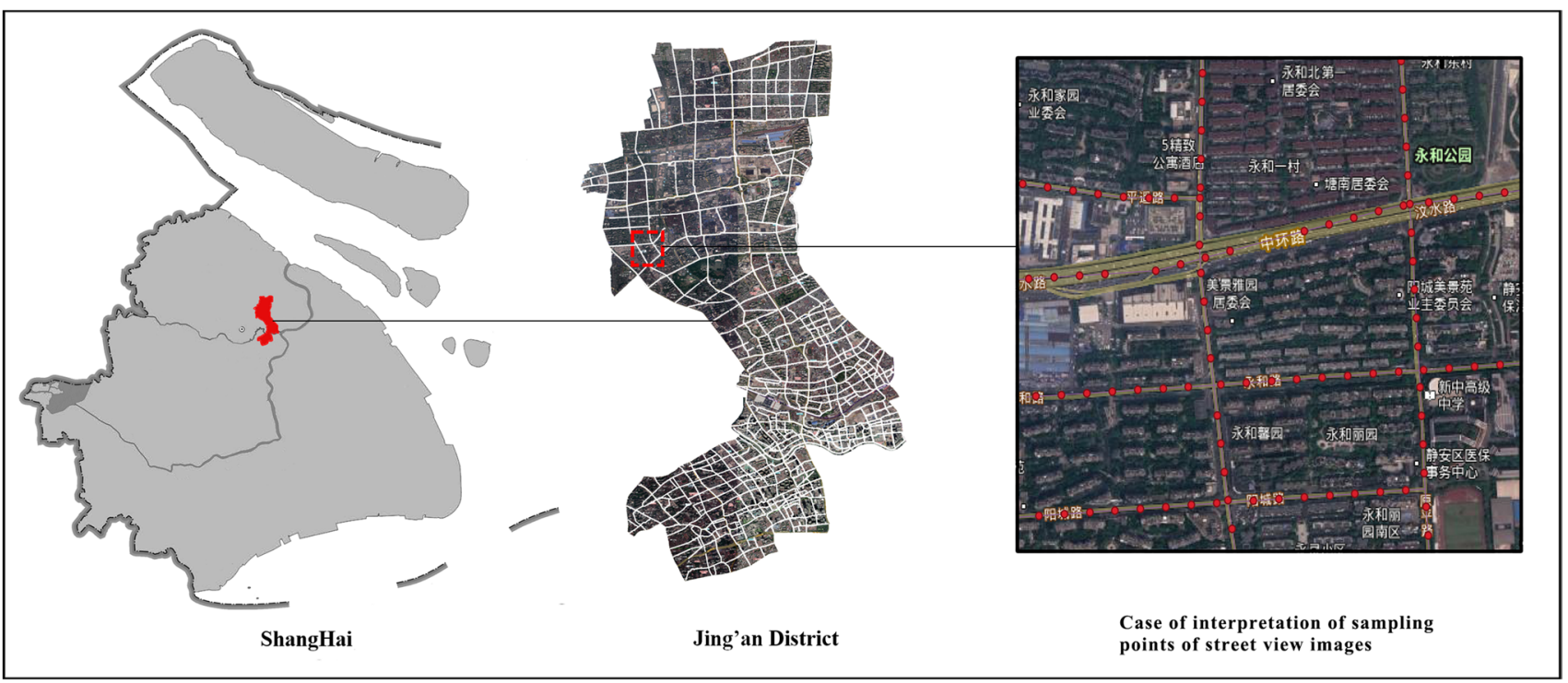

Fig. 1 The site and sampling points across the street network. Case study area Jing'an district, Shanghai. The white lines in the right subplot are the main roads in the study area obtained from openstreetmap.org

Funding National Natural Science Foundation of China (51978329, 51778364)

Publisher's Note Springer Nature remains neutral with regard to jurisdictional claims in published maps and institutional affiliations.

The original article has been corrected. 